\title{
Effects of the Addition of Calcium Acetate into Silicate-Based Electrolytes on the Properties of MAO Coatings Produced on Zirconium
}

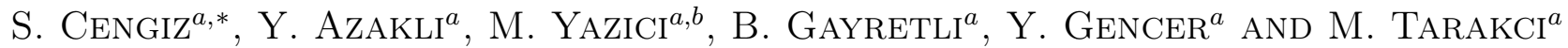 \\ ${ }^{a}$ Gebze Technical University, Department of Materials Science and Engineering, 41400 Gebze, Kocaeli, Turkey \\ ${ }^{b}$ Ondokuz Mayis University, Department of Materials Science and Engineering, 55139 Kurupelit, Samsun, Turkey
}

\begin{abstract}
Zirconium (Zr) is a potential implant material due to its excellent biocompatibility and low elastic modulus for biomedical applications. Its poor bioactivity, however, limits its use as biomaterials. In this study, microarc oxidation which is a plasma-electrochemical based process was applied to produce oxide coatings on pure zirconium. The coating processes were conducted in different electrolytes containing sodium silicate and varying amounts of calcium acetate monohydrate (CA) for $30 \mathrm{~min}$ to investigate the effect of the introduction of CA into the electrolyte solution on the morphology and chemical composition of the fabricated coatings. It was found that the coatings consisted of monoclinic- $\mathrm{ZrO}_{2}$ and tetragonal- $\mathrm{ZrO}_{2}$ phases. The amount of the tetragonal- $\mathrm{ZrO}_{2}$ phase increased with the increasing CA concentration in the electrolyte. The coating thickness and surface roughness showed a tendency to increase with the increasing CA concentration in the electrolyte. It was observed that the vicinity of plasma channels were Zr-rich, while their surroundings were rich in $\mathrm{Si}$ and Ca elements. The outer region of the coating was denser compared to inner region consisting of Zr-rich porous structure.
\end{abstract}

DOI: 10.12693/APhysPolA.129.504

PACS/topics: 81.15.-z, 81.05.Bx

\section{Introduction}

Zirconium and its alloys are potential materials to be used in medical applications because of their outstanding mechanical properties, biocompatibility and high corrosion resistance [1-3]. However, the bio-inert nature of $\mathrm{Zr}$ and $\mathrm{Zr}$-based materials hinders their use in surgical and dental applications [4]. Therefore, the bioactivity of these materials is required to be improved. This problem can be addressed by taking advantage of various surface coating technologies to produce bioactive materials on $\mathrm{Zr}$. Among the various surface coating methods, microarc oxidation (MAO), also known as plasma electrolytic oxidation (PEO), one of the possible coating methods that can be used for coating zirconium, has attracted great deal of attention in the last couple of years. Using the MAO method, well-adhered surface coatings with high corrosion and wear resistance can be fabricated on various metals including $\mathrm{Al}, \mathrm{Ti}, \mathrm{Zr}$, and $\mathrm{Mg}$. The quality of the MAO coatings is dependent on various process parameters, such as duration of the coating process, applied power, voltage, and current density implemented for the oxidation of the substrate, composition of the substrate and electrolyte solution. Although much work has been conducted on the microarc oxidation of light metals including $\mathrm{Al}, \mathrm{Ti}, \mathrm{Mg}$, and their alloys, microarc oxidation of $\mathrm{Zr}$ and $\mathrm{Zr}$-based materials is still in an infant stage $[1,5-16]$. Therefore, understanding the effect of

*corresponding author; e-mail: scengiz@gtu.edu.tr calcium acetate addition into electrolytes as a Ca source is crucial to modify the surface chemistry of coatings obtained on zirconium for possible bio-applications.

In this study, the effects of the electrolyte used in the MAO process on the morphology and chemical composition of the coating surfaces are reported. In our previous studies, the MAO of pure zirconium was carried out in electrolytes with different amounts of sodium silicate [14]. Our studies revealed that the fabricated coating layers consisted of $\mathrm{m}-\mathrm{ZrO}_{2}$ and $\mathrm{t}-\mathrm{ZrO}_{2}$ phases and the increasing amount of sodium silicate concentration in the electrolyte solution resulted in an increase in both the amount of $\mathrm{t}-\mathrm{ZrO}_{2}$ phase and the coating thickness [14]. We also examined the effects of the introduction of yttrium acetate tetrahydrate (YAT) into a sodium silicate-containing electrolyte on the properties of the produced coating layers. It was observed that oxide-based coatings were formed on pure zirconium in YAT-introduced electrolyte. The coating/substrate interface became smoother and surface roughness tended to decrease as the amount of YAT in electrolytic solution increased. The XRD results indicated that the coatings were mainly composed of $\mathrm{m}-\mathrm{ZrO}_{2}$ and $\mathrm{t}-\mathrm{ZrO}_{2}$ phases [17]. It was reported that the increasing amount of sodium aluminate $(8-32 \mathrm{~g} / \mathrm{l})$ in the electrolyte resulted in a higher coating growth rate and the main phases in the coatings were found to be $\mathrm{t}-\mathrm{ZrO}_{2}$ and $\gamma-\mathrm{Al}_{2} \mathrm{O}_{3}[18]$.

While the corrosion and the wear resistance of $\mathrm{Zr}$ and $\mathrm{Zr}$-based materials can be improved by the fabrication of $\mathrm{ZrO}_{2}$-based surface coatings, the bio-inert nature of the produced coatings remains as a challenge to be addressed for biomedical applications. Recent studies showed that the bioactivity of the implant materials can be enhanced 
by the modification of the surface of these materials with $\mathrm{Ca}, \mathrm{P}, \mathrm{Ti}, \mathrm{Si}$, and $\mathrm{Na}[1,2,9,10]$. It was reported that the growth and the adhesion of behavior of osteogenic cells were enhanced by the fabrication of Ca-based coatings [19]. In the present work, MAO coatings were produced on zirconium substrates in sodium silicate containing electrolytes with varying amount of calcium acetate monohydrate (CA, 2-8 g/l). The fabricated coatings were characterized by scanning electron microscopy (SEM) with energy-dispersive X-ray spectroscopy (EDS), profilometry, and X-ray diffractometry (XRD) to investigate the effects of the composition of the electrolyte solution on the physicochemical properties of the coatings.

\section{Experimental}

The pure zirconium sheet $(99.5 \%)$ was cut to rectangular shaped specimens with the dimensions of $25 \mathrm{~mm} \times$ $50 \mathrm{~mm} \times 0.71 \mathrm{~mm}$ (Alfa Aesar). The samples were ground using 240-1200 grit SiC paper and then polished using 3-1 $\mathrm{\mu m}$ alumina suspension. After grinding and polishing, the substrates were cleaned in an ultrasonic bath of ethanol for $5 \mathrm{~min}$. The surface roughness of the substrates was measured from an area of $5 \mathrm{~mm} \times 5 \mathrm{~mm}$ with 10 scans by employing Dektak 8 Profilometer. The electrolytes with four different compositions were prepared using a certain amount of sodium silicate and CA by dissolving in distilled water as given in Table I. These electrolyte compositions were hereinafter referred to as A1, A2, A3 and A4 in the paper.

\section{TABLE I}

The chemical composition of the electrolytes.

\begin{tabular}{c|c|c|c|c}
\hline \hline Electrolyte composition & A1 & A2 & A3 & A4 \\
\hline sodium silicate $[\mathrm{g} / \mathrm{l}]$ & 12 & 12 & 12 & 12 \\
Calcium acetate monohydrate $[\mathrm{g} / \mathrm{l}]$ & 0 & 2 & 4 & 8
\end{tabular}

The coating process was carried out by means of a homemade $\mathrm{MAO}$ unit with an asymmetric $\mathrm{AC}$ power supply $(50 \mathrm{~Hz})$ with the maximum capacity of $100 \mathrm{kVA}$. The coating formation voltages were $480 \mathrm{~V}$ (anode) and $120 \mathrm{~V}$ (cathode). The coating duration for each sample was $30 \mathrm{~min}$. After coating, samples were consecutively washed in distilled water and in ethanol then dried under warm air flow. The surface roughness of the MAO coated samples was evaluated by using the same Profilometer with the same parameters used for uncoated Zr. Rigaku D-MAX 2200 X-ray diffractometer $(40 \mathrm{~kW}, 40 \mathrm{~mA})$, with a $\mathrm{Cu} K_{\alpha}$ radiation over a $2 \theta=10^{\circ}$ to $90^{\circ}$, was employed for the characterization of coating. The surfaces and the chemical composition of MAO coated samples were examined using Phillips XL30 scanning electron microscope (SEM) with energy-dispersive X-ray spectroscopy (EDS). Then the samples were cut, mounted into epoxy resin, ground (240-1200 grit SiC paper) and polished (3$1 \mu \mathrm{m}$ colloidal alumina) to expose the cross-section of the coatings. Cross-sectional microstructure examination and determination of the chemical composition of the MAO coated samples were also carried out by SEM with regional EDS analysis.

\section{Result and discussion \\ 3.1. Coating thickness and surface roughness}

Figure 1 illustrates the measurements of the average coating thickness and surface roughness $(\mathrm{Ra})$ of the coatings formed on $\mathrm{Zr}$ in different electrolytes of A1, A2, A3 and A4. Maximum coating thickness was measured on A3 as $38 \mu \mathrm{m}$ with an average value of $35 \mu \mathrm{m}$. Average thickness values of A1 (without CA), A2, A4 were measured as $20,26,32 \mu \mathrm{m}$, respectively. The average surface roughness values varied from $3.5 \mu \mathrm{m}$ to $6 \mu \mathrm{m}$ depending on the electrolytic solution while the surface roughness of the bare zirconium substrate before coating was approximately $0.16 \mu \mathrm{m}$. It can also be seen from the figure that increasing amount of $\mathrm{CA}$ in electrolyte increased both coating thickness and surface roughness values. At longer coating durations, as a result of the powerful electrical discharges, high strong electron avalanches occur, thus, the spark formation at the outer portion make the surface rough.

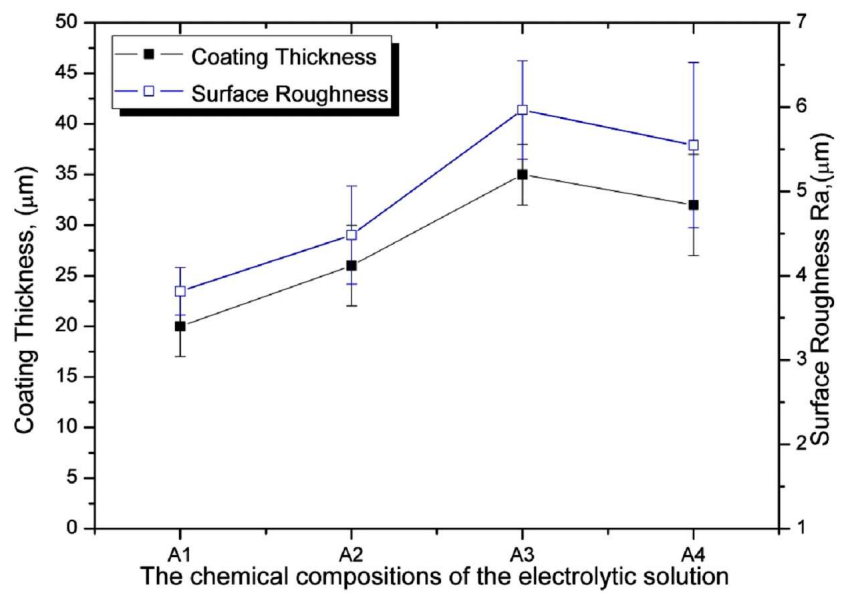

Fig. 1. The change in the coating thickness and surface roughness $(\mathrm{Ra})$ with MAO coating of $\mathrm{Zr}$ in different electrolytes.

\subsection{Phase analysis of coatings}

XRD spectra obtained from the surface of the MAO coatings formed in A1, A2, A3 and A4 electrolytes are given in Fig. 2. XRD spectra show that the coatings were composed of $\mathrm{m}-\mathrm{ZrO}_{2}$ and $\mathrm{t}-\mathrm{ZrO}_{2}$ phases for $\mathrm{A} 2$, $\mathrm{A} 3$ and A4 coatings. Also the relative intensity of the peaks belong to $\mathrm{m}-\mathrm{ZrO}_{2}$ decreases while that of $\mathrm{t}-\mathrm{ZrO}_{2}$ phase increases depending on increasing $\mathrm{CA}$ concentration in the electrolyte. $\mathrm{ZrO}_{2}$ can be present in three different crystal structures depending on the different temperature intervals (monoclinic, tetragonal, cubic) while only $\mathrm{m}-\mathrm{ZrO}_{2}$ is stable at room temperature under equilibrium conditions [20]. The transformation of monoclinic to tetragonal phase occurs at $1170^{\circ} \mathrm{C}$ and from tetragonal to cubic transformation occurs at $2370^{\circ} \mathrm{C}$. When the temperature of molten metal and metal-oxide suddenly decrease, $\mathrm{ZrO}_{2}$ phases can be stabilized in various 
crystal structures because of rapid cooling. For example, if the temperature of the coating decreases below $1200^{\circ} \mathrm{C}$, because of the contact with cold electrolyte, non-equilibrium transformation of $\mathrm{t}-\mathrm{ZrO}_{2}$ to $\mathrm{m}-\mathrm{ZrO}_{2}$ occurs. Though $\mathrm{t}-\mathrm{ZrO}_{2}$ is a high temperature phase, its stabilization at room temperature was attributed to several mechanisms such as reduction of grain size, residual compressive stresses and existence of oxides in the $\mathrm{Zr}$ $\mathrm{O}$ phases like $\mathrm{MgO}, \mathrm{Y}_{2} \mathrm{O}_{3}$ and $\mathrm{CaO}$ [17]. However, the clear effect of $\mathrm{CA}$ addition on the XRD peaks obviously resulted in dominance of $\mathrm{t}-\mathrm{ZrO}_{2}$ phase in the coating surface in this study (Fig. 2). Hence, it is not difficult to conclude that infiltration of $\mathrm{CaO}$ from the electrolyte into the coating and then the existence in the crystal structure of $\mathrm{Zr}-\mathrm{O}$ resulted in the stabilization of $\mathrm{t}-\mathrm{ZrO}_{2}$ phase in the coating.

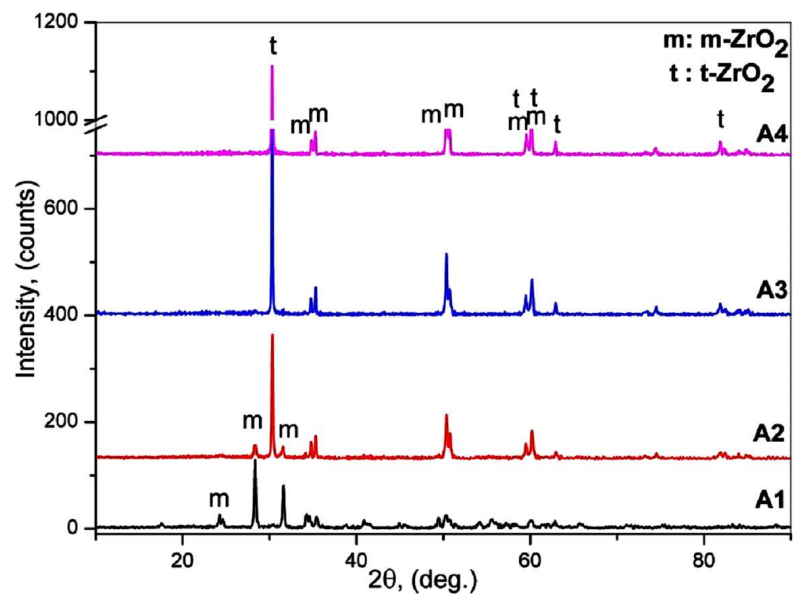

Fig. 2. The surface XRD patterns of MAO coating formed on zirconium substrate in different electrolytes.

\subsection{Microstructure of the coating}

The SEM micrographs showing microstructures of the coatings obtained from the surface and of the MAO coated samples in A1, A2, A3, and A4 solutions were given in Fig. $3 \mathrm{a}-\mathrm{d}$, respectively. Cross-sectional SEM images of the samples coated in Fig. 4a-d were given in electrolyte A1, A2, A3, and A4, respectively. Pores, micro and macro-cracks can be seen on the surfaces of all coatings. The surface of the oxide coatings became rougher and pores tended to enlarge with increase of CA concentration in the electrolyte. Formation of these pores could be the result of the gas bubbles and molten metal-oxide thrown out of spark discharged channels. Pancake-like features were observed on the surface of MAO coated samples (Fig. 3a). The relatively big holes in the center of the pancake features indicate that intense spark discharges were generated during the process. No cracks were observed on the surface of coating with A1 electrolyte (Fig. 3a), whereas some cracks are evident on the surface of coatings with A2-A4 electrolytes (Fig. 3b-d) those containing $\mathrm{CA}$.

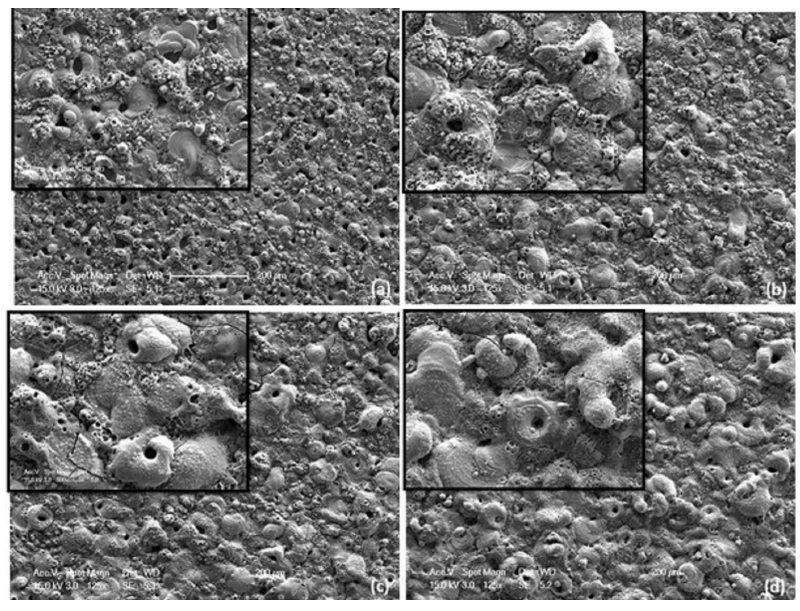

Fig. 3. The surface SEM micrographs of MAO coated $\mathrm{Zr}$ in different electrolytes: (a) A1, (b) A2, (c) A3, and (d) A4.

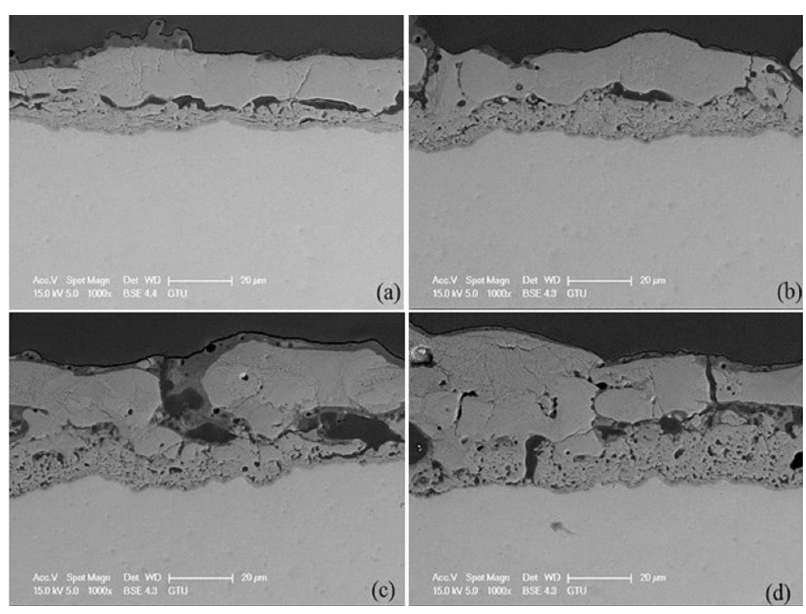

Fig. 4. The cross-section SEM micrographs of MAO coated $\mathrm{Zr}$ in different electrolytes: (a) A1, (b) A2, (c) A3, and (d) A4.

The presence of these cracks can be attributed to thermal stresses in discharge channels due to rapid cooling of melted materials on the surface. Addition of further CA to the electrolyte resulted in high porosity in the coating and probable formation of compounds with lower thermal conductivity. It is also seen in Fig. $4 \mathrm{a}-\mathrm{d}$ that cracks are present directed towards to the surface of the coating. Moreover, the largest pores are observed in the border of the outer and inner region on these cross-sectional SEM images of the coating. This behavior also implies that the formation mechanism of the coating layer is a combination of inwards and outwards growth (Fig. 4). The existence of porous layer near the substrate suggests the inwards growth of coating towards the substrate while the increase of the dense layer on the surface of the coating implies the outwards growth of the coating [21].

\subsection{Chemical analysis of the coating}

Figure 5 illustrates typical surface SEM image of the coating formed in electrolyte A4 with regional SEM-EDS 
spectra (Fig. 5b-d) for main constituents of O, Si, Ca, Zr, $\mathrm{Na}$ acquired from three regions marked as " 1 ", "2", and "3" in Fig. $5 \mathrm{a}$ in the coatings. According to the SEM-EDS results, region " 1 " is rich in silicon and calcium while the regions "2" and " 3 " are rich in zirconium. The presence of high content of $\mathrm{Zr}$ at the regions " 2 " and " 3 " is attributable to the transportation of the molten materials through the discharge channels where the ejaculated molten metal from the depth of the coating meets the electrolyte at the vicinity of pancake features. Hence, high content of zirconium was detected in the surrounding of the discharge channels. However, the spreading molten materials exposed to electrolyte relatively longer time and/or the confinement of more electrolyte residues in the coating in the areas far from the discharge channels like region " 1 " resulted in the presence of more $\mathrm{Si}$ and $\mathrm{Ca}$ on the surface of the coating (Fig. 5a).
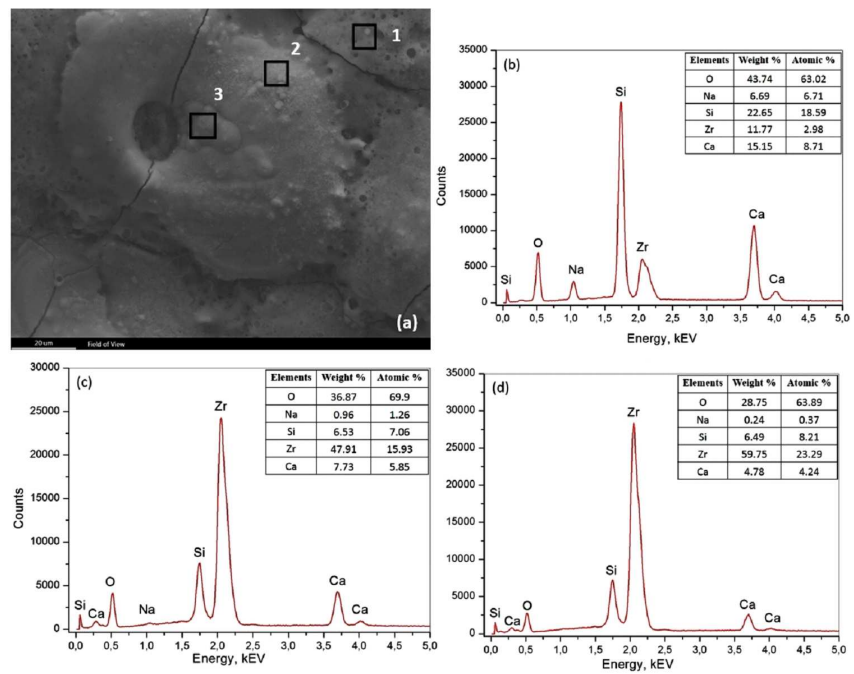

Fig. 5. Surface SEM micrograph of MAO coating of $\mathrm{Zr}$ in electrolyte A4 and the SEM-EDS spectra from its certain areas: (a) SEM image, (b) area "1" and (c) area "2", (d) area " 3 ".

A typical cross-sectional SEM image (Fig. 6a) together with SEM-EDS spectra obtained from its marked areas of "X", "Y", and "Z" is given in Fig. 6b-d, respectively. The SEM-EDS spectra show the presence of $\mathrm{O}, \mathrm{Si}, \mathrm{Zr}$ and $\mathrm{Ca}$ elements in the coating. Although the relative amount of $\mathrm{Zr}$ element is almost the same in porous inner regions ("Y" in Fig. 6c and "Z" in Fig. 6d), it dramatically decreases in dense outer region ("X" in Fig. 6b) where the amount of $\mathrm{Si}$ and $\mathrm{Ca}$ are relatively higher while the relative amount of $\mathrm{O}$ is nearly constant in the three regions. These results show that the elements present in the electrolyte were transferred to the coating. Especially Si, Ca elements are dominantly effective and it is not difficult to conclude that the outer dense region of the coating was formed by the complex reaction of these elements with the constituents in the coating.

The existence of high amount of $\mathrm{Ca}$ in the coating is a promising finding of this study from the bioactivity point
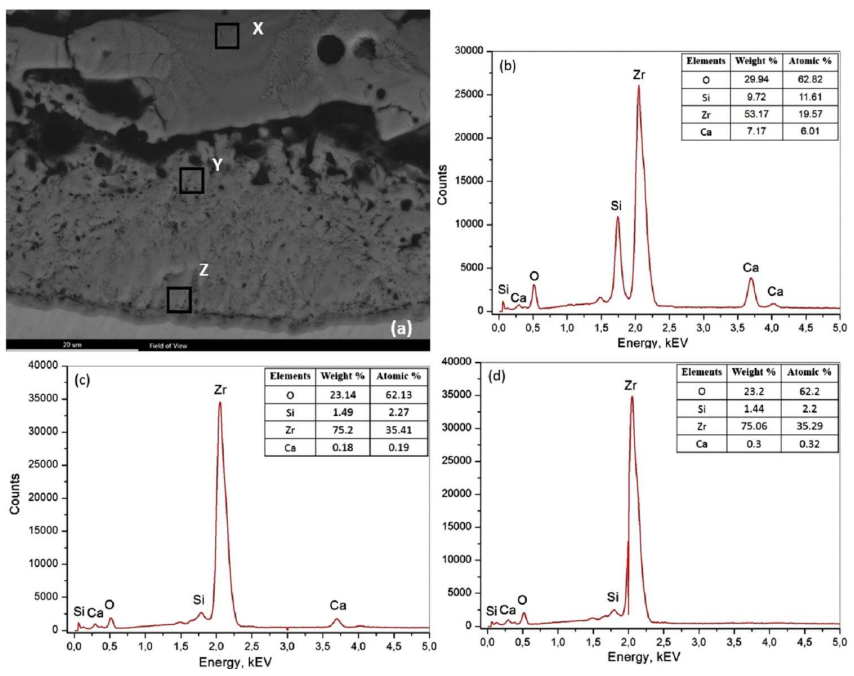

Fig. 6. Cross-sectional SEM micrographs of MAO coating of $\mathrm{Zr}$ in electrolyte A4 and the SEM-EDS spectra from its certain areas: (a) SEM image, (b) area "X", (c) area "Y" and (d) area "Z".

of view as the presence of the Ca may positively affect the bioactivity of the material.

\section{Conclusions}

The oxide based coatings were produced on pure zirconium for the duration of 30 min by MAO method in the different electrolytes containing sodium silicate and different amounts of $\mathrm{CA}$ and the following conclusions were obtained:

- The coatings phase constituents are mainly affected by the existence of $\mathrm{CA}$ in the electrolyte.

- The more $\mathrm{CA}$ in electrolyte, the more formation $\mathrm{t}-\mathrm{ZrO}_{2}$ phase in the coating occurs.

- The thickness and roughness of the coating increases with increasing CA concentration in the electrolyte.

- The vicinity of plasma channels which are in the form of pan cake are in rich in $\mathrm{Zr}$, while their far surroundings are rich in $\mathrm{Si}, \mathrm{Ca}$.

- The dense outer region of the coating is rich in $\mathrm{Si}$ and Ca while the relatively porous inner region is rich in $\mathrm{Zr}$.

\section{Acknowledgments}

This research was supported by Gebze Technical University (project number: BAP-2014-A21)

\section{References}

[1] M. Sandhyarani, N. Rameshbabu, K. Venkateswarlu, D. Sreekanth, C. Subrahmanyam, J. Alloy Comp. 553, 324 (2013).

[2] P. Thomsen, C. Larsson, L.E. Ericson, L. Sennerby, J. Lausmaa, B. Kasemo, J. Mater. Sci-Mater. M. 8, 653 (1997). 
[3] J. Chevalier, Biomaterials 27, 535 (2006).

[4] M. Uchida, H.M. Kim, T. Kokubo, K. Tanaka, T. Nakamura, J. Ceram. Soc. Jpn. 110, 710 (2002).

[5] S. Cengiz, M. Tarakci, Y. Gencer, A.O. Devecili, Y. Azakli, Acta Phys. Pol. A 123, 445 (2013).

[6] Y. Gencer, M. Tarakci, A.E. Gulec, Z.C. Oter, Acta Phys. Pol. A 125, 659 (2014)

[7] S. Cengiz, Y. Gencer, Surf. Coat. Technol. 242, 132 (2014)

[8] Y. Gencer, A.E. Gulec, J. Alloys Comp. 525, 159 (2012).

[9] X.N. Gu, N. Li, W.R. Zhou, Y.F. Zheng, X. Zhao, Q.Z. Cai, L.Q. Ruan, Acta Biomater. 7, 1880 (2011).

[10] W.B. Xue, C. Wang, R.Y. Chen, Z.W. Deng, Mater. Lett. 52, 435 (2002).

[11] L.R. Krishna, A.S. Purnima, N.P. Wasekar, G. Sundararajan, Metall. Mater. Trans. A 38A, 370 (2007).

[12] M. Sandhyarani, T. Prasadrao, N. Rameshbabu, Appl. Surf. Sci. 317, 198 (2014).

[13] K.M. Lee, Y.S. Kim, H.W. Yang, J.H. Park, Y.G. Ko, D.H. Shin, Mater. Charact. 99, 101 (2015).
[14] Y. Gencer, M. Tarakci, S. Cengiz, K.O. Gunduz, Adv. Mater. Res.-Switz. 445, 637 (2012).

[15] Y. Gencer, M. Tarakci, S. Cengiz, J. Fac. Eng. Archit. Gaz. 26, 851 (2011).

[16] S. Cengiz, A. Uzunoglu, L. Stanciu, M. Tarakci, Y. Gencer, Surf. Coat. Technol., 2015, in press.

[17] S. Cengiz, M. Yazici, Y. Gencer, M. Tarakci, Acta. Phys. Pol. A 127, 1320 (2015).

[18] Y.L. Cheng, J.H. Cao, Z.M. Peng, Q. Wang, E. Matykina, P. Skeldon, G.E. Thompson, Electrochim. Acta 116, 453 (2014).

[19] M. Sandhyarani, N. Rameshbabu, K. Venkateswarlu, L.R. Krishna, Surf. Coat. Technol. 238, 58 (2014).

[20] E. Matykina, R. Arrabal, P. Skeldon, G.E. Thompson, P. Wang, P. Wood, Surf. Coat. Technol. 204, 2142 (2010).

[21] R.O. Hussein, X. Nie, D.O. Northwood, A. Yerokhin, A. Matthews, J. Phys. D Appl. Phys. 43, 105203 (2010). 